\title{
MODELLING OF A MULTI MOTORS TRACTION SYSTEM CONNECTED IN SERIES USING A MATRIX CONVERTER
}

\author{
Selimane MEGUENNI ${ }^{1}$ and Abdelkader DJAHBAR ${ }^{2}$ \\ ${ }^{1}$ Department of Technology, University of HASSIBA BEN BOUALI CHLEF, \\ Algeria, \\ Electrical Engineering Laboratory and renewable energy LEGER
}

\begin{abstract}
The first generation of multi-machine systems is limited on two .the first configuration consists of a continuous floor which feeds several three-phase inverters connected in parallel, or each inverter supplies a three-phase machine .the control of each machine is independent via its inverter and its algorithm control .the second configuration consists of a single inverter, which also feeds in parallel three phase machines .for this structure, the machines must have the same speed and suffer the same torque load these two conditions make the use of this system in a limited scope. It is impossible to connect in series several three-phase machines powered by a single-phase power converter and that each machine in the group have an independent speed control .but, the use of multi-phase converters associated with polyphase machine. generate additional degrees of freedom. With these, several polyphase machines can be connected in series in an appropriate transposition phases.
\end{abstract}

The objective of this work is to order, model and characterize the behavior of a training system multimachines composed of two five phase synchronous permanent magnet motors connected in series and powered by a five phase matrix converter applied to the rail traction.

\section{KEYWORDS}

synchronous machine, Multi-machine Multi-inverter, five-phase, vector control,

\section{INTRODUCTION}

Thanks to the advances in technology and the means of calculating the powerful, it is possible to consider the variable speed applications in an efficient manner where the association of electrical machines and of static converters are more and more applications in embedded systems (ships, submarines, vehicles, aircraft...etc.), where the gain in space and weight requires a very particular attention. An example of the systems of drives, which combine the advantages offered by the use of multiphase machinery, of the electronic power and the means of calculation, is the SMM systems which allows you to order in a way completely decoupled several electrical machines whose windings are connected in series.

The traction systems electric railway are complex, they have electrical couplings, magnetic and mechanical solid. These couplings impose a number of constraints that complicate the modelling and analysis of these systems. Multi Machine / System Multi-converter systems (MMS) used to meet the industrial requirements such as the optimization of the system volume and weight. 
Several configurations are developed and analyzed in order to guarantee the stability of operation when a mechanical disturbance or electric appears.

In this approach, we focus in particular on the modeling and the independent control of the two five phase synchronous permanent magnet motors connected in series.

\section{DESCRIPTION AND MODELING OF THE SYSTEM:}

The use of a structure composed of two engines powered by a single static converter, allows one hand to reduce the number of components of power and control, and on the other hand, to establish a command for the entirety of the bogie of traction. In this study the overall system consists of two five phase motor synchronous with permanent magnet connected in series. Therefore many configurations are possible. The first consists of a continuous floor which supplies several three-phase inverters mounted in parallel, or each inverter supplies a three phase motors. The control of each engine is independent via its inverter and its control algorithm. The second configuration consists of a single converter, which moreover supplies in parallel several Engines. For this structure, the engines must have the same speed of rotation and suffer the same load torque.

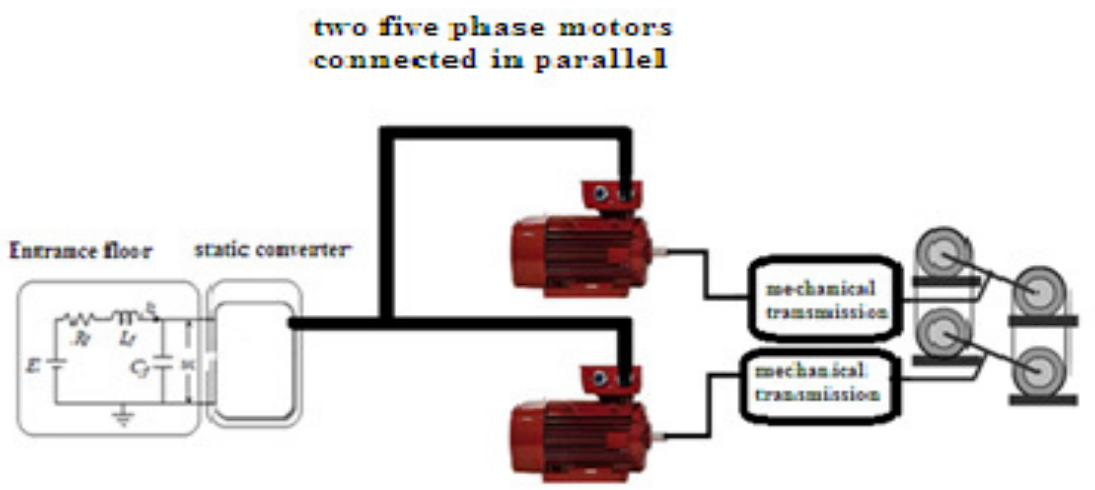

Fig .1: Block diagram with a command structure of the configuration parallel for the chain of rail traction.

A new structure of propulsion is proposed. It consists of a inverter to seven levels of voltage to pulse width modulation, feeding in series with the two five phase motors.

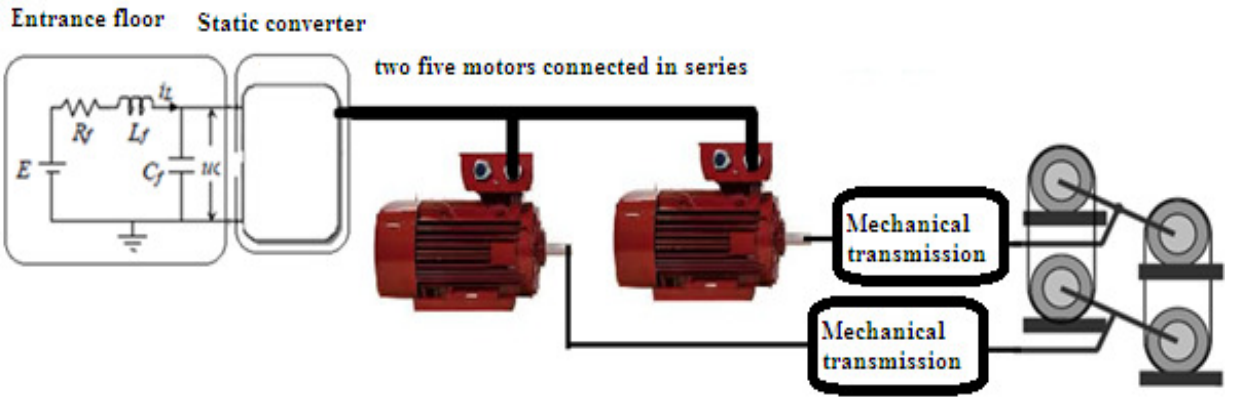

Fig .02: Block diagram with a command structure proposed for the chain of rail traction. 


\section{MODELING OF TWO FIVE PHASE MOTORS SYNCHRONOUS WITH PERMANENT MAGNET CONNECTED IN SERIES:}

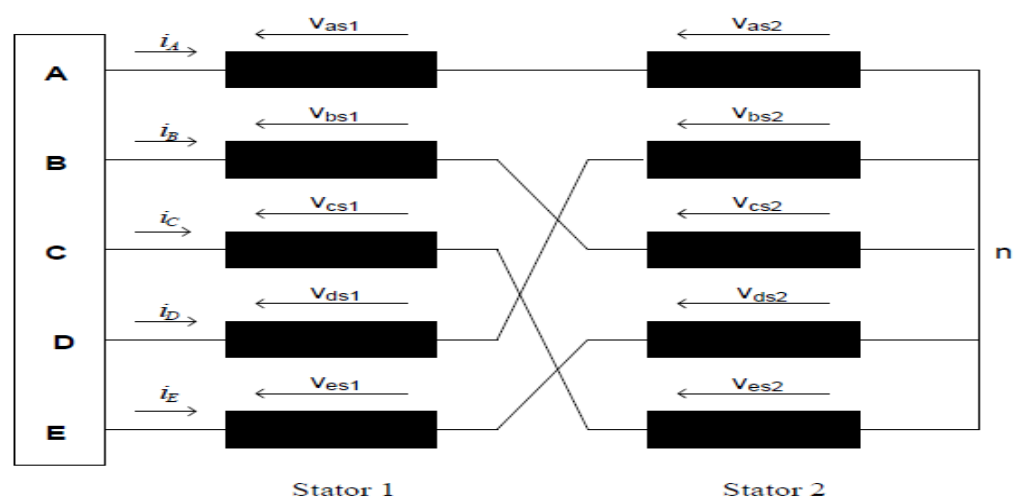

Fig .03: description of two five phase motor connected in series.

According to the connection diagram of the fig(3), where the phase voltages of the two machines are defined, voltages of the inverter phase-neutral (A, B, C, D, E to NEUTRAL (N) and the relationship between the output current of the ups and currents of the phases of the two machines are provided with:

$$
\left[V_{s}\right]=\left[\begin{array}{c}
v_{A} \\
v_{B} \\
v_{C} \\
v_{D} \\
v_{E}
\end{array}\right]=\left[\begin{array}{l}
v_{a s 1}+v_{a s 2} \\
v_{b s 1}+v_{c s 2} \\
v_{c s 1}+v_{e s 2} \\
v_{d s 1}+v_{b s 2} \\
v_{e s 1}+v_{d s 2}
\end{array}\right] \quad(1) \quad \begin{aligned}
& i_{A}=i_{a s 1}=i_{a s 2} \\
& i_{B}=i_{b s 1}=i_{c s 2} \\
& i_{C}=i_{c s 1}=i_{e s 2} \\
& i_{D}=i_{d s 1}=i_{b s 2} \\
& i_{E}=i_{e s 1}=i_{d s 2}
\end{aligned}
$$

The two machines of Fig (3) are assumed to be of the same parameters, the electrical circuit of the model of the fig (3) it can be represented as a matrix form (quantities not linear) by:

$$
\left[V_{\mathrm{ABCDE}}\right]=\left[R_{\mathrm{S}}\right]\left[I_{\mathrm{ABCDE}}\right]+\frac{d}{d t}\left[\phi_{\mathrm{ABCDE}}\right]
$$

\subsection{Transformation of decoupling of Clark:}

The relationship between the original variables of the phases and the new variables $(\alpha \beta x y)$ is given by:

$$
f(\alpha \beta)^{\prime}=[C] f(A B C D E)
$$

Where $[C]$ is the transformation matrix to invariant Power: 
International Journal of Applied Control, Electrical and Electronics Engineering (IJACEEE) Vol 4, No. 2/3, August 2016

$$
\left[C_{s}\right]^{t}=\sqrt{\frac{2}{5}}\left[\begin{array}{cllll}
1 & \cos (\alpha) & \cos (2 \alpha) & \cos (3 \alpha) & \cos (4 \alpha) \\
0 & \sin (\alpha) & \sin (2 \alpha) & \sin (3 \alpha) & \sin (4 \alpha) \\
1 & \cos (2 \alpha) & \cos (4 \alpha) & \cos (6 \alpha) & \cos (8 \alpha) \\
0 & \sin (2 \alpha) & \sin (4 \alpha) & \sin (6 \alpha) & \sin (8 \alpha) \\
1 / \sqrt{ } 2 & 1 / \sqrt{2} & 1 / \sqrt{2} & 1 / \sqrt{2} & 1 / \sqrt{2}
\end{array}\right]
$$

Applying this matrix tension vector inverter there will:

$$
\left[\begin{array}{l}
v_{\alpha}^{i n v} \\
v_{\beta}^{i n v} \\
v_{x}^{i n v} \\
v_{y}^{i n v} \\
v_{o}^{i n v}
\end{array}\right]=\left[\begin{array}{ll}
C & {[}
\end{array}\right]\left[\begin{array}{l}
v_{A} \\
v_{B} \\
v_{C} \\
v_{D} \\
v_{E}
\end{array}\right]
$$

Using this matrix to the relation (1), The tensions of each machine in this mark:

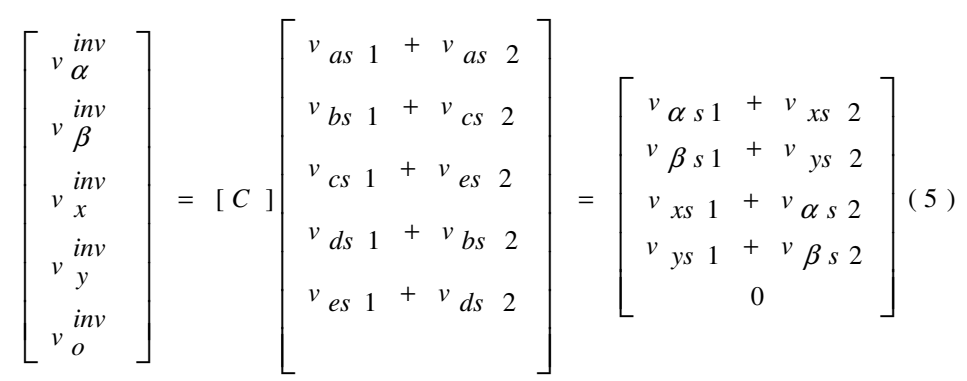

The relationship between the output current of the ups and currents $\alpha-\beta, x-y$ of the two machines is:

$$
\begin{aligned}
& i_{\alpha}^{I N V}=i_{\alpha} 1=i_{X} 2 \\
& { }_{\beta}^{I N V}=i_{\beta 1}=-i_{Y} 2 \\
& i_{X}^{I N V}=i_{X} 1=i_{\alpha} 2 \\
& { }_{Y}^{I N V}=i_{Y} 1=i_{\beta} 2
\end{aligned}
$$

As the sub-Space $\alpha-\beta$ is orthogonal to the sub- space $X-Y$, it follows that the specific method of the serial connection used in the Fig (3) will allow the vector command independent of the two machines.

$$
\left[V_{\mathrm{ABCDE}}\right]=\left[R_{\mathrm{s}}\right]\left[I_{\mathrm{ABCDE}}\right]+\frac{d}{d t}\left(\left[L_{s}\right]\left[i_{A B C D E}\right]+\left[\phi_{\text {aimant }}\right]\right.
$$

The component of order zero for the converter can also be well neglected. The Electromagnetic part of the drive system can then be represented with eight equations of the first order. The four equations of the converter are as follows: 


$$
\begin{aligned}
& v_{\alpha}^{I N V}=\left(R_{s 1}+R_{s 2}\right) i_{\alpha}^{I N V}+\left(l_{s 1}+\frac{5}{2} m_{s 1}\right) \frac{d}{d t} i_{\alpha}^{I N V}+l_{s 2} \frac{d}{d t} i_{\alpha}^{I N V}-\sqrt{\frac{5}{2}} \omega_{1} \phi_{f 1} \sin \left(\theta_{1}\right) \\
& v_{\beta}^{I N V}=\left(R_{s 1}+R_{s 2}\right) i_{\beta}^{I N V}+\left(l_{s l}+2 m_{s 2}\right) \frac{d}{d t} i_{\beta}^{I N V}+l_{s 2} \frac{d}{d t} i_{\beta}^{I N V}+\sqrt{\frac{5}{2} \omega_{1} \phi_{f 1} \cos \left(\theta_{1}\right)} \\
& v_{x}^{I N V}=\left(R_{s 1}+R_{s 2}\right) i_{X}^{I N V}+l_{s 1} \frac{d}{d t} i_{x}^{I N V}+\left(l_{s 2}+\frac{5}{2} m_{s 2}\right) \frac{d}{d t} i_{x}^{I N V}-\sqrt{\frac{5}{2}} \omega_{2} \phi_{f 2} \sin \left(\theta_{2}\right) \\
& v_{y}^{I N V}=\left(R_{s 1}+R_{s 2}\right) i_{y}^{I N V}+l_{s 1} \frac{d}{d t} i_{y}^{I N V}+\left(l_{s 2}-\frac{5}{2} m_{s 2}\right) \frac{d}{d t} i_{y}^{I N V}+\sqrt{\frac{5}{2}} \omega_{2} \phi_{f 2} \cos \left(\theta_{2}\right)
\end{aligned}
$$

\subsection{Model in a rotary index:}

In order to express all sizes in a single frame, the stator variables are projected into a rotating reference frame $(d, q)$ shifted by $\varphi$ with respect to the fixed coordinate system $(\alpha, \beta)$, this transformation is calculated from the matrix $\mathrm{D}$ rotation as:

$$
\mathrm{D}=\left[\begin{array}{cc}
\cos (\theta) \sin (\theta) & \cdot \\
\sin (\theta) \cos (\theta) & \dot{\cdot} \\
\cdot & {[I] 3 * 3}
\end{array}\right]
$$

In terms of the different components of the tensions of stator d-q of two machines:

$$
\begin{aligned}
& v_{d}^{I N V}=v_{d s} 1+v_{x s} 2 \\
& v_{q}^{I N V}=v_{q s} 1+v_{d s} 2 \\
& v_{x}^{I N V}=v_{x s} 1+v_{y s} 2 \\
& v_{y}^{I N V}=v_{y s} 1+v_{q s} 2
\end{aligned}
$$

Couple relations between the two series-connected machines are given in terms of current components of the matrix converter:

$$
\begin{aligned}
& C_{e 1}=p\left(\left(L_{d}-L_{q}\right) i_{d}^{I N V} i_{q}^{I N V}+\sqrt{\frac{5}{2}} \phi_{f 1} i_{q}^{I N V}\right) \\
& C_{e 2}=p\left(\left(L_{x}-L_{y}\right) i_{x}^{I N V} i_{Y}^{I N V}+\sqrt{\frac{5}{2}} \phi_{f 2} i_{y}^{I N V}\right)
\end{aligned}
$$

\section{VECTOR CONTROL OF TWO FIVE PHASE MOTOR CONNECTED IN SERIES:}

To a voltage supply via a voltage-controlled inverter, the reference voltages are created by adding the reference voltages of each machine are:

For the machine 1:

$$
\begin{aligned}
& v_{d}^{I N V}=\left(R_{s 1}+R_{s 2}\right) i_{d}^{I N V}+\left(l_{s 1}+\frac{5}{2} m_{s 1}\right) \frac{d}{d t} i_{d}^{I N V}+l_{s 2} \frac{d}{d t} i_{d}^{I N V}-\omega_{1}\left(l_{s 1}+\frac{5}{2} m_{s 1}\right) i_{q}^{I N V} \\
& v_{q}^{I N V}=\left(R_{s 1}+R_{s 2}\right) i_{d}^{I N V}+\left(l_{s l 1}+\frac{5}{2} m_{s 1}\right) \frac{d}{d t} i_{q}^{I N V}+l_{s 2} \frac{d}{d t} i_{q}^{I N V}+\omega_{1}\left(l_{s 1}+\frac{5}{2} m_{s 1}\right) i_{d}^{I N V}+\sqrt{\frac{5}{2}} \omega_{1} \phi_{f 1}
\end{aligned}
$$

DOI: $10.5121 /$ ijaceee.2016.4301 
For the machine 2:

$$
\begin{aligned}
& v_{x}^{I N V}=\left(R_{s 1}+R_{s 2}\right) i_{X}^{I N V}+l_{s 1} \frac{d}{d t} i_{x}^{I N V}+\left(l_{s 2}+\frac{5}{2} m_{s 2}\right) \frac{d}{d t} i_{x}^{I N V}-\omega_{2}\left(l_{s 2}+\frac{5}{2} m_{s 2}\right) i_{y}^{I N V} \\
& v_{y}^{I N V}=\left(R_{s 1}+R_{s 2}\right) i_{y}^{I N V}+l_{s 1} \frac{d}{d t} i_{y}^{I N V}+\left(l_{s 2}-\frac{5}{2} m_{s 2}\right) \frac{d}{d t} i_{y}^{I N V}+\omega_{2}\left(l_{s 2}+\frac{5}{2} m_{s 2}\right) i_{x}^{I N V}+\sqrt{\frac{5}{2}} \omega_{2} \phi_{f 2}
\end{aligned}
$$

Couple relations between the two series-connected machines are given in terms of current components of the inverter:

$$
\begin{aligned}
& C_{e 1}=p\left(\left(L_{d}-L_{q}\right) i_{d}^{I N V} i_{q}^{I N V}+\sqrt{\frac{5}{2}} \phi_{f 1} i_{q}^{I N V}\right) \\
& C_{e 2}=p\left(\left(L_{x}-L_{y}\right) i_{x}^{I N V} i_{Y}^{I N V}+\sqrt{\frac{5}{2}} \phi_{f 2} i_{y}^{I N V}\right)
\end{aligned}
$$

Both equations are completely independent, so we can control each machine with two and vector control using a single matrix converter.

The couple first machine controlled by the two currents (id, iq) and. for the second machine torque controlled by both current (ix, iy).Among control strategies, one that is often used is to maintain I_D component and zero i_x. We control couples only by iq iy and currents. Thus rule speeds by ix and iy component.

The overall voltage references are then formed on the wiring diagram of fig (3), where as:

$$
\begin{aligned}
& v_{A}^{*}=v_{\text {as }}^{*}{ }^{*}+v_{\text {as }}^{*}{ }^{*} \\
& v_{B}^{*}=v_{b s}^{*}{ }_{b s}^{*}+v_{c s}^{*}{ }_{c}^{*} \\
& v_{C}^{*}=v_{c s}^{*}{ }_{c s}^{*}+v_{e s}^{*} 2 \\
& v_{D}^{*}=v_{d s}^{*}{ }_{d s}^{*}+v_{b s}^{*} 2 \\
& v_{E}^{*}=v_{e s}^{*}{ }_{e s}^{*}+v_{d s}^{*}{ }_{2}^{*}
\end{aligned}
$$

Use of the matrix with the equation gives:

$$
\begin{aligned}
& i_{\alpha}^{I N V}=i_{\alpha 1}=i_{X 2} \\
& i_{\beta}^{I N V}=i_{\beta 1}=-i_{Y 2} 2 \\
& i_{X}^{I N V}=i_{X 1}=i_{\alpha 2} \\
& i_{Y}^{I N V}=i_{Y 1}=i_{\beta 2}
\end{aligned}
$$

A system illustration of the vector control of two five phase motors is given in fig.(04) 


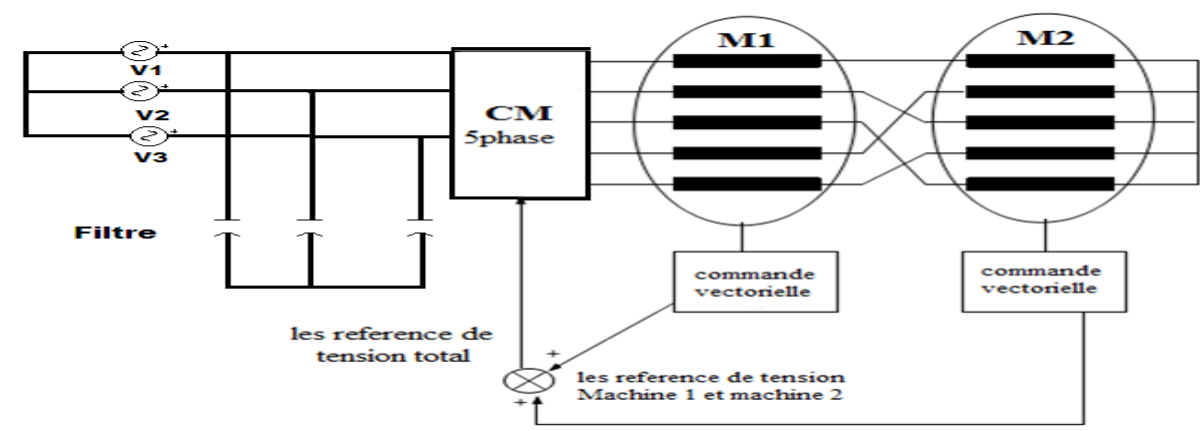

Fig. 04: Block diagram of vector control two five phase motors connected in series powered by a

\section{SIMULATION RESULTS:}
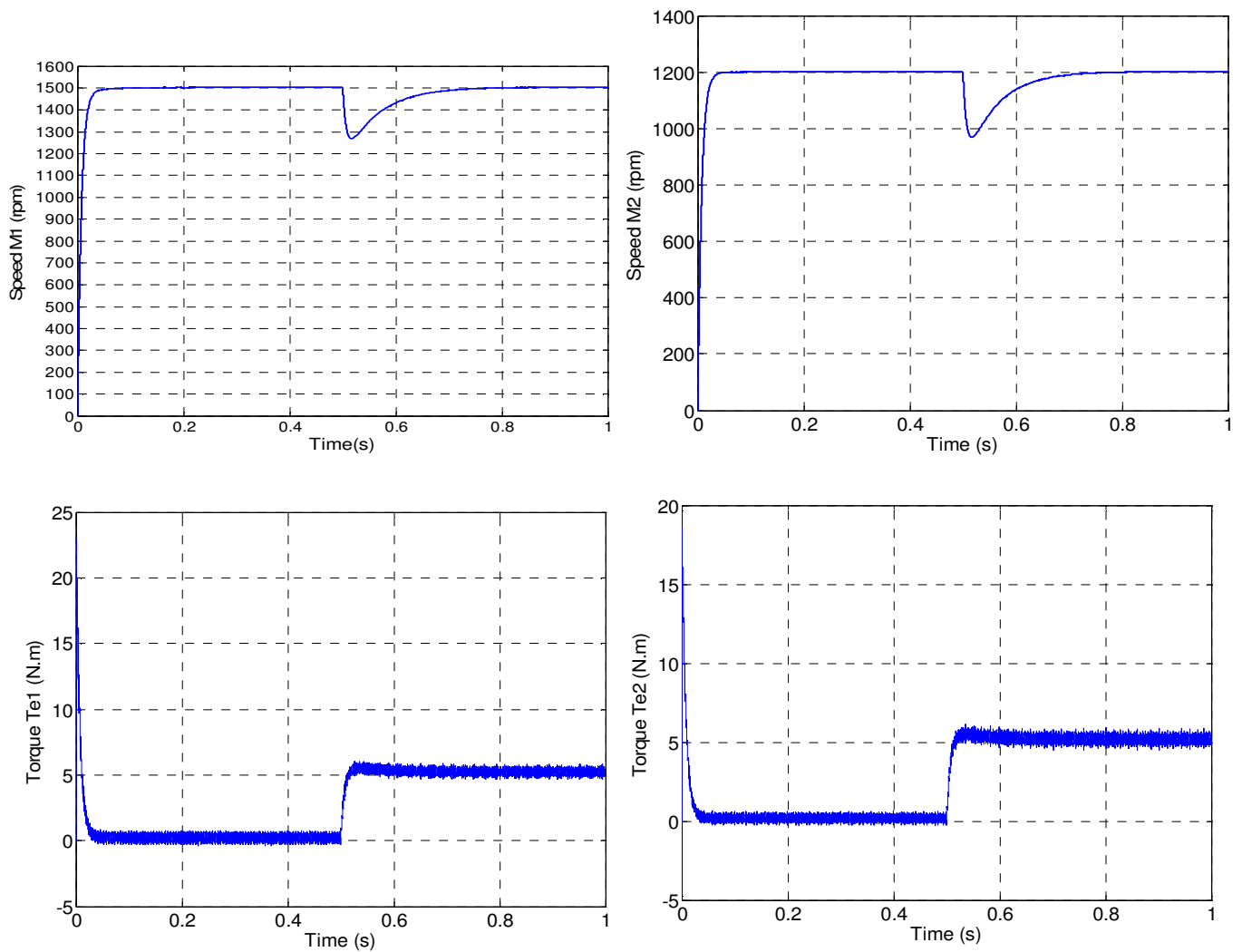

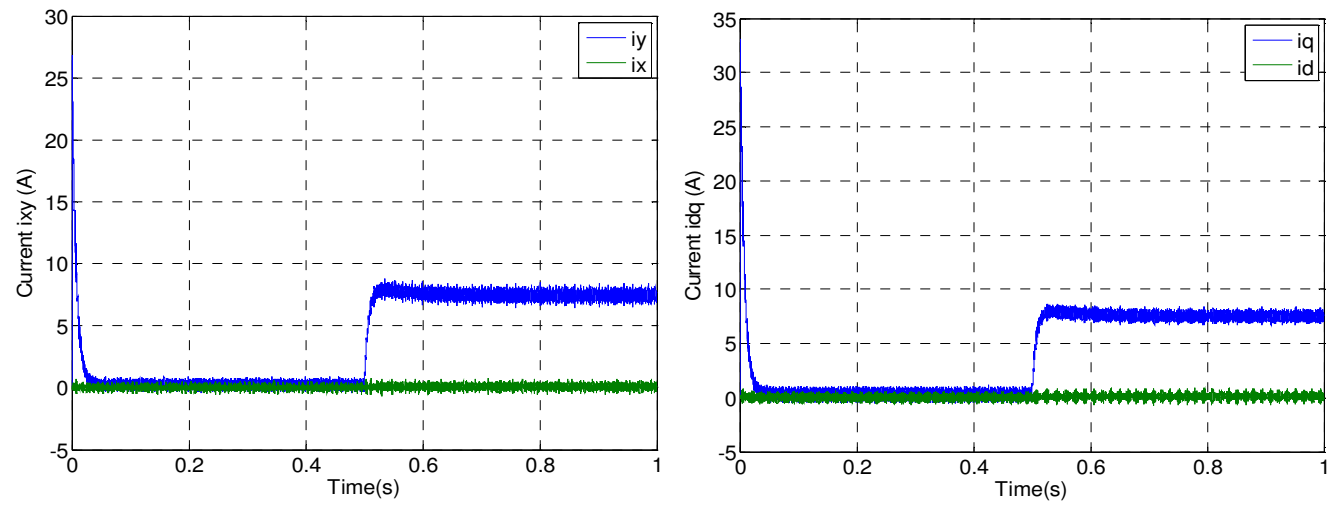

Fig.05: Responses of the PMSM connected in series with a load of $05 \mathrm{Nm}$ at $0.5 \mathrm{~s}$ and a step change of two speed order(1500 rpm and $1200 \mathrm{rpm})$
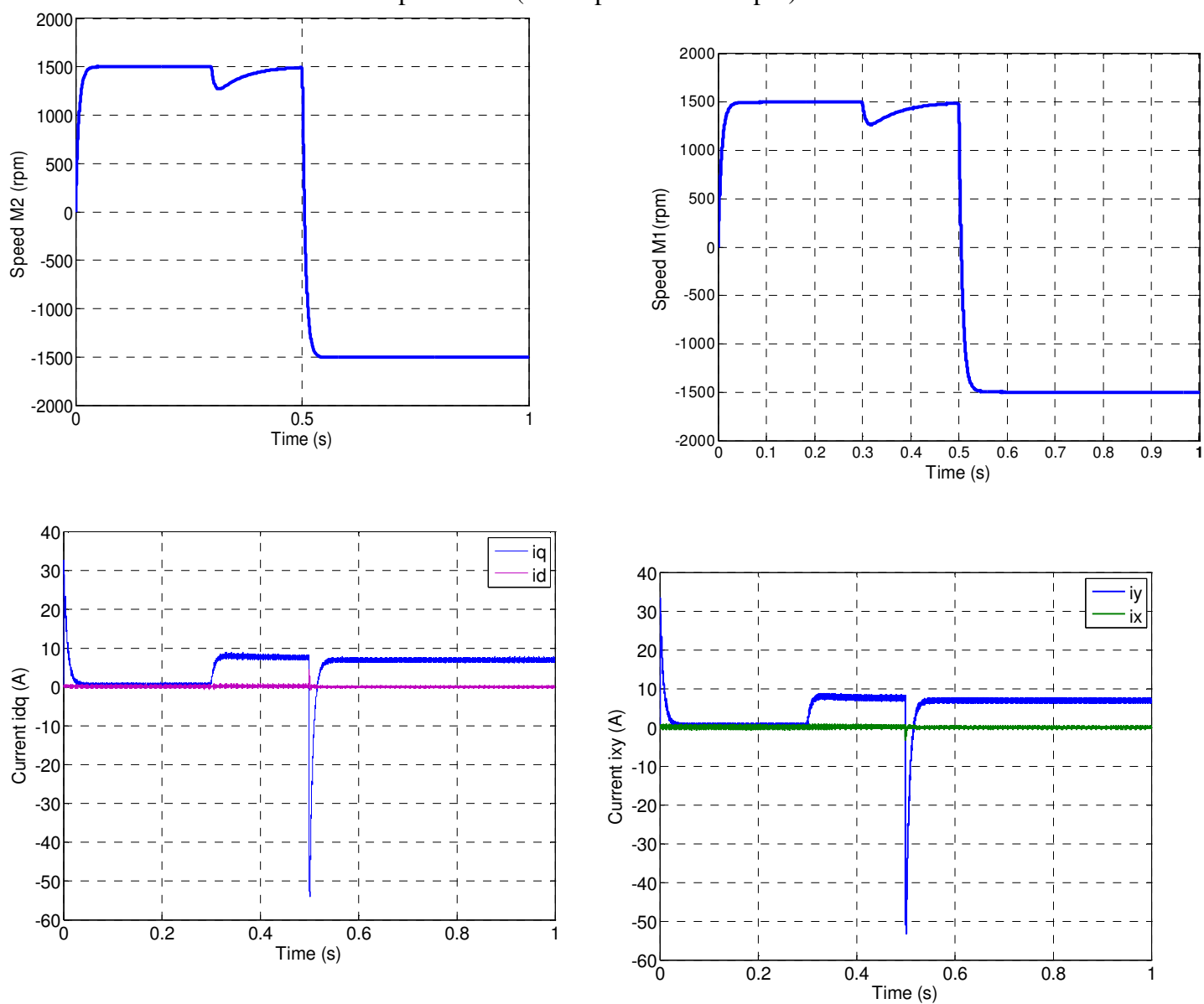

Fig.06: responses of the PMSM connected in series with a load of $05 \mathrm{Nm}$ and a step change of the reference speed from $1500 \mathrm{rpm}$ to $-1500 \mathrm{rpm}$ at $\mathrm{t}=0.5 \mathrm{~s}$ 
Tab .1: Five phase PMSM Parameters

\begin{tabular}{|l|c|c|c|c|c|c|}
\hline \multicolumn{1}{|c|}{$R_{s}$} & $L_{d}$ & $L_{q}$ & $j$ & $\mathrm{p}$ & $\varphi_{f}$ & $f_{r}$ \\
\hline 3.6 & 0.0021 & 0.0021 & 0.0011 & 2 & 0.12 & 0 \\
$\mathrm{ohm}$ & $\mathrm{H}$ & $\mathrm{H}$ & $\mathrm{kg} / \mathrm{m}^{2}$ & & web & hertz \\
\hline
\end{tabular}

\section{CONCLUSION:}

In this approach, we tested in simulation vector control applied to two five phase synchronous machines permanent magnets connected in series powered by a five phase voltage matrix converter we note that:

- the pace of speed perfectly follows its reference which is reached very quickly with an acceptable response time. The effect of the disturbance is quickly removed and the electromagnetic torque stabilizes at a value of 5 N.m.

- The response of the two components of the current shows decoupling introduced by vector control of two five phase machines.

- The current Iq is the image of the torque 1.

- The current Iy is the image of torque2.

The transposition of two machines has allowed us to have more degree of freedom on the axes of currents and so ordered two machines independently.

The independent vector control two machines gave good results and helped to decouple control flow and torque for both machines. This allowed controlling several machines in series and with different types of polyphase machines.

\section{REFERENCES}

[1] M. Jones, E. Levi and A. Iqbal, "A Five-Phase Series-Connected Two- Motor Drive with Current Control in the Rotating Reference Frame", 2004 35th Annul IEEE Power Electronics Specialists Conference, Aochen. Gemany, 2004.

[2] E. Levi, A. Iqbal, S. N. Vukosavic and H. A. T'oliyat, "Modeling and Control of a Five-Phase SeriesConnected Two-Motor Drive", IEEE, 2003.

[3] E. Semail, E. Levi, A. Bouscayrol, X. Kestelyn, «Multi-Machine Modelling of Two Series Connected 5phase Synchronous Machines: Effect of Harmonics on Control », IEEE-IAS'04, Seattle (Washington), October 2004,

[4] E. Levi, M. Jones, S. N. Vukosavic, A. Iqbal, and H. A. Toliyat, "Modeling, control, and experimental investigation of a five-phase series-connected two-motor drive with single inverter supply," IEEE Trans. Ind. Electron. Jun. 2007.

[5] W. Ben Mabrouk, J. Belhadj, M. Pietrzak-David, "Modelling and Control of electromechanical Multi machine System for Railway Traction”, 2nd International conference on Electrical Engineering Design and Technologies, ICEEDT, 8-10, 2008, Hammamet Tunisia.

[6] A. Bouscayrol, M. Pietrzak-David, P. Delarue, R. Peña-Eguiluz, P. E. Vidal, X. Kestelyn, "Weighted control of traction drives with parallel connected AC machines", IEEE Trans. on Industrial Electronics, Vol.: 53, no6, pp. 1799-1806, December 2006.

[7] R. Peña-Eguiluz, M. Pietrzak-David, B. de Fornel, "Enhanced locomotive drive system behaviour applying a single voltage source inverter dual induction motor structure", EPE Journal, vol. 15, no 2, to be published in 2005 . 
[8] E. Levi, M. Jones, S.N. Vukosavic, H.A. Toliyat, "A novel concept of a multi-phase, multi-motor vector controlled drive system supplied from a single voltage source inverter," IEEE Transactions on Power Electronics, vol. 19, 2004, pp. 320-335.

[9] E. Levi, M. Jones, S. N. Vukosavic, and H. A. Toliyat, "A five phase two machine vector controlled induction motor drive supplied from a single inverter," Eur. Power Electron. (EPE) Drives J., vol. 14, no. 3, pp. 38-48,2004.

[10] P. Pillay and R. Krishnan, "Application characteristics of permanent magnet synchronous and brushless dc motors for servo drives," IEEE Transaction on Industry Electronics, vol. 27, pp. 984-996,Sept./Oct. 1991.

[11] A. Consoli, G. Scarcella, and A. Testa, "Industry application of zerospeed sensorless control techniques for pm synchronous motors," IEEE Transactions on Industry Applications, vol. 37, pp. 513-521, March-April 2001.

[12] Parsa, L, Toliyat, H A, "Sensorless direct torque control of five phase interior permanent magnet motor drives," Industry Applications Conference, 2004. 39th IAS Annual Meeting. Conference Record of the 2004 IEEE, Vol. 2, 2004: 992-999.

[13] Hamid A. Toliyat, "Analysis and Simulation of Five-Phase Variable-Speed Induction Motor Drives Under Asymmetrical Connections", IEEE Trans. On Power Electr., Vol. 13, No. 4, JULY 1998, pp. 748-756.

[14] E. Levi, M. Jones, S. N. Vukosavic, A. Iqbal, and H. A. Toliyat, "Modeling, control, and experimental investigation of a five-phase series connected two-motor drive with single inverter supply," IEEE Trans. Ind.

[15] E. Levi, M. Jones, S. N. Vukosavic, and H. A. Toliyat, "Steady state modeling of series-connected fivephase and six-phase two-motor drives," in Conf. Rec. IEEE IAS Annu. Meeting, Tampa, FL, 2006, pp. 415-422.

[16] M. Jones, E. Levi, and A. Iqbal, "Vector control of a five-phase series connected two-motor drive using synchronous current controllers," Elect. Power Comput. Syst., vol. 33, no. 4, pp. 411-430, Feb. 2005 